\title{
PEMANFAATAN WEBINAR DALAM BIDANG KEPERAWATAN
}

\author{
Syarifatul Izza*, Bhekti SetyaNingrum, Rr. Tutik Sri Hariyati \\ Magister Kepemimpinan dan Manajemen Keperawatan, Fakultas Ilmu Keperawatan, Universitas Indonesia, \\ Kampus FIK UI, Jl. Prof. Dr. BahdderDjohan, Depok, Jawa Barat, Indonesia 16424 \\ *izzabii08@gmail.com (+6281381748177)
}

\begin{abstract}
ABSTRAK
Sistem Informasi Kesehatan merupakan bagian yang penting bila dikaitkan dengan perkembangan dalam bidang kesehatan. Teknologi ini membuka peluang untuk berinteraksi dengan berbagai audiens untuk memberikan strategipendidikan baru dalam dunia keperawatan. Dengan penyebaran teknologi informasi dan kemajuan internet, pendidikan telah berubah dan pembelajaran onlinemenjadi berkembang pesat. Salah satunya adalah dengan pemanfaatan Webinar. Pelajaran berbasis webinar dengan pendidikan berkelanjutan melalui internet. Teknologi Webinar memiliki banyak manfaat di bidang pembelajaran online, memungkinkan untuk komunikasi realtime dan sinkron antara pembicara dan pendengar, mencakup jarak jauh untuk menjangkau audiens potensial, dan memungkinkan untuk mengarsipkan informasi berbasis web untuk digunakan nanti.Penelitian ini menggunakan perangkat penelitian PICO (Population, Intervention, Comparison, Outcome). Data diambil dari berbagai jurnal dari tahun 2010 sampai tahun 2019 tentang penielitian terkait pelaksanaan webinar pada perawat dan mahasiswa keperawatan. Penelitian ini menunjukan bahwa penggunaan Webinar dapat meningkatkan pengetahuan dan pengalaman perawat dalam proses pembelajaran.
\end{abstract}

Kata kunci: education, e-learning, literature review, penelitian, teknologi, webinar

\section{WEBINAR UTILIZATION IN NURSING}

\begin{abstract}
Health Information System is an important part when it is associated with developments in the health sector. This technology opens opportunities to interact with various audiences to provide new educational strategies in the world of nursing. With the spread of information technology and the advancement of the internet, education has changed and online learning is developing rapidly. One way is to use Webinars. Webinar-based learning with continuing education via the internet. Webinar technology has many benefits in the field of online learning, allows for realtime and synchronous communication between speaker and listener, covers long distances to reach potential audiences, and makes it possible to archive web-based information for later use. This research uses the PICO research tool (Population, Intervention, Comparison, Outcome). Data was taken from various journals from 2010 to 2019 about research related to the implementation of webinars for nurses and nursing students. This research shows that the use of webinars can enhance nurses' knowledge and experience in the learning process.
\end{abstract}

Keywords: education, e-learning, literature review, research, technology, webinars 


\section{PENDAHULUAN}

Praktik keperawatan adalah layanan yang dilakukan oleh perawat untuk memberikan asuhan keperawatan kepada klien. Perawat harus memberikan asuhan keperawatan kepada pasien atau klien sesuai dengan dasar ilmiah. Hal ini sesuai dengan ketentuan Undang-Undang No 38 Tahun 2014 tentang Keperawatan. Tujuan dari ilmu terapan ini adalah untuk memberikan perawatan yang tepat kepada pasien karena tanpa itu asuhan keperawatan tidak dapat diimplementasikan dengan baik. Untuk dapat memberikan perawatan yang tepat, seorang perawat harus mengembangkan pengetahuan dan kemampuannya dalam melakukan tindakan keperawatan (Eslamian, Moeini, and Soleimani, 2015).

Pelayanan kesehatan telah berubah selama dekade terahir. Namun, pendidikan keperawatan belum mengimbangi kemajuan sosial dan ilmiah. Berdasarkan laporan Institute of Medicine, The Future of Nursing: Leading Change, Advancing Health (Gorski et al., 2015) menyatakan bahwa tenaga keperawatan yang lebih berpendidikan dapat meningkatkan pengetahuan profesional. Namun, fenomena baru-baru ini menunjukan bahwa perawat di fasilitas kesehatan cenderung belum mampu mengejar ketinggalan dengan perawat dibidang pendidikan. Perawat dari bidang pendidikan selalu mempunyai update pengetahuan terbaru tentang perawatan yang efektif dan efisien. Jika hal ini terus terjadi, maka pemberian asuhan keperawatan hanya akan didasarkan pada kebiasaan atau instruksi dari dokter tanpa intervensi otonom. Fenomena ini disebabkan oleh banyak faktor,
Menurut Renol et al. (2018), menyatakan dalam penelitiannya bahwa jumlah perawat yang berlebihan mempengaruhi keinginan mereka untuk memperbaharui pengetahuan dan keterampilan klinis mereka. Studi lain menunjukan adanya penurunan pendanaan dan peningkatan beban kerja menjadi kendala perawat dalam menemukan literatur tentang prosedur standar operasional terbaru. Revolusi industri 4.0 juga menjadikan tantangan baru bagi perawat untuk tetap mendapatkan informasi terbaru dengan memanfaatkan kemajuan teknologi informasi. Globalisasi dan teknologi baru memperluas cakrawala kita dengan potensi untuk menghubungkan orangorang dari berbagai lokasi.

Berdasarkan penelitian yang dilakukan oleh Alvara Research Center (2016), pada tahun 2015 pengguna internet di Indonesia mencapai 93,4 juta pengguna dan akan terus tumbuh hingga 2019 yang akan mencapai 133,5 juta pengguna. Pada tahun 2020 Indonesia akan mencapai 140 juta pengguna internet, Indonesia akan menjadi pasar digital paling signifikan di Asia Tenggara pada tahun 2020. Dengan kata lain, dengan adanya kemajuan teknologi di era 4.0 ini dapat berkembang menjadi wadah atau alat untuk meningkatkan pendidikan dalam keperawatan. Webinar adalah salah satu cara untuk menjawab tantangan pengetahuan perawat di era revolusi indistri 4.0. Webinar merupakan salah satu program e-learning atau elektronik edukasi. Webinar merujuk pada metode pendidikan online sinkron di mana orang berkumpul pada waktu tertentu untuk mendengarkan, mengamati, dan berpartisipasi dalam presentasi suatu topik. Istilah "webinar" diusulkan oleh Eric R. Kolb pada tahun 1998 yang 
merupakan perpaduan dari kata "web" dan "seminar" (Lande, 2011). Pelajaran berbasis webinar dan pendidikan berkelanjutan dilakukan melalui internet di mana setiap orang harus dilengkapi dengan komputer atau ponsel pintar. Komunikasi video tersedia melalui monitor dan webcam dan setiap orang dapat berkomunikasi dengan guru melalui komputer. Sejauh ini pemanfaatan webinar telah diterapkan di berbagai bidang pendidikan, tetapi dalam bidang praktik klinik keperawatan penggunaan webinar belum optimal. Meskipun beberapa rumah sakit telah mengembangkan program webinar. Tujuan dari tinjauan literature review ini adalah untuk mengetahui pemanfaatan webinar dalam bidang keperawatan.

\section{METODE}

Metode dalam penelitian ini menggunakan kajian literatur menggunakan perangkat PICO (population, intervention, comparison dan outcome). Perangkat ini didesain untuk membantu peneliti saat membuat pertanyaan penelitian dan memungkinkan mendapatkan kajian literatur yang lebih khusus. Proses pendidikn keperawatan ini adalah dengan cara melihat video atau percakapan interaktif berbasis internet dan video atau Skype, yang mana narasumber bisa dari negara atau kota manapun sehingga tidak perlu menghadiri lokasi seminar atau pembelajaran. Denangan metode webinar ini juga tetap bisa melakukan proses tenya jawab secara langsung.

Perangkat pertanyaan dalam penelitian ini adalah pendidikan keperawatan dengan populasi mahasiswa keperawatan, perawat ruangan dalam intervensi webinar dengan perbandingan standar pendidikan perawat yang akan di dapatkan hasil tingkat pengetahuan perawat lebih meningkat dan pengeluaran akan anggaran pendidikan di luar kota atau luar negeri dapat berkurang.

Adapun sumber yang dapat diakses untuk penelitian adalah EBSCO, ProQuest, ADFM, ELSEVIER, TQR, ADFM, dengan kata kunci, webinar for nursing, education,e-learning. Kriteria inklusi padapenelitian ini adalah: perawat di RS, mahasiswa keperawatan, sumber data diambil dari tahun 2010 sapai dengan 2019.

\section{HASIL}

Pelajaran berbasis webinar dan pendidikan berkelanjutan dilakukan melalui Internet di mana setiap orang harus dilengkapi dengan komputer atau ponsel pintar. Komunikasi video tersedia melalui monitor dan webcam dan setiap orang dapat berkomunikasi dengan guru melalui komputer. Teknologi Webinar memiliki banyak manfaat di bidang pembelajaran online, memungkinkan untuk komunikasi realtime dan sinkron antara pembicara dan pendengar, mencakup jarak jauh untuk menjangkau audiens potensial, dan memungkinkan untuk mengarsipkan informasi berbasis web untuk digunakan.

Penelitian yang dilakukan oleh Joshi et al. (2013) menunjukan bahwa secara keseluruhan, 90,1\% menunjukan bahwa konten webinar relevan dengan minat dan kebutuhan dalam bidang keperawatan. Penelitian lain menunjukan bahwa peserta webinar melaporkan tingkat kepuasan yang sangat tinggi dengan aksesbilitas, ruang lingkup, kuallitas, dan interaktivitas dari program pengembangan profesional. Menurut hasil penelitian tentang The Development of a Brief Suicide Screening 
and Risk Assessment Training Webinar for Rural Primary Care Practices menyatakan bahwa mayoritas responden setuju atau sangat setuju $(73,3 \%)$ bahwa program webinar itu relevan dengan praktik keperawatan, $(81,3 \%)$ mudah diikuti, dan $(75,0 \%)$ mereka akanmerekomendasikannya kepada sesama profesional(LeCloux, 2018). Studi Dalhem dan Saleh (2014) tentang dampak webinar pada perawat oleh 70 perawat menyatakan bahwa $47,1 \%$ perawat menyatakan kepuasan dan webinar memiliki efek positif pada peningkatan kinerja perawat dalam melakukan asuhan keperawatan. Sebuah studi yang dilakukan oleh Bahrambeygi et al. (2018) Menunjukkan efektivitas program e-learning menunjukkan tingkat pemahaman dan perilaku peduli pada perawat meningkat. Selain itu, sebuah penelitian berpendapat bahwa semakin luas pengetahuan perawat, semakin baik perilaku merawat perawat yang akan mempengaruhi kepuasan pasien. Di Indonesia, pemanfaatan webinardilakukan di RSCM, RSAB, Kariadi dan Sarjito. Menurut pengamatan setiap rumah sakit, webinar diadakan pada waktu yang berbeda tergantung pada jadwal mereka, dan mereka juga menyediakan berbagai sarana dan prasarana. Selain itu, rumah sakit ini menetapkan kriteria mereka yang dapat menghadiri webinar mereka. Webinar dapat berpartisipasi melalui komputer atau ponsel. Namun, program ini tidak termasuk evaluasi pengetahuan perawat karena hanya dilakukan dalam satu hari (Nilasari, 2018).

\section{PEMBAHASAN}

Pengajaran berbasis webinar dalam layanan kesehatan adalah pendekatan yang diadopsi oleh semakin banyak spesialisasi, suatu penelitian tentang persepsi siswa tentang hasil belajar dari webinar peer learning antar budaya yang telah dilakukan olehClarison et al. (2017) menunjukan bahwa penggunaan webinar dan pembelajaran kolaboratif akan memungkinkan pertukaran international yang terjadi diantara siswa dari berbagai dunia, dimana tidak terdapat batasan dalam proses pembelajarannya. Ini sama pentingnya untuk meningkatkan pemahaman budaya global tentang keperawatan yang universal dan dapat dikenali. Dalam penelitian ini salah satu batasannya adalah bahwa belum ada pelaporan mengenai kendala-kendala teknis yang dialami siswa selama menggunakan webinar. Semua ini bersandar pada kualitas koneksi atau jaringan yang digunakan.

Hasil dari penelitian tentang persepsi siswa keperawatan tentang hasil belajar dari webinar dan peer learning, menekankan bahwa penggunaan webinar dan pembelajaran kolaboratif akan memungkinkan pertukaran siswa secara internasional dimana tidak ada batasan untuk mengaksesnya. Ini sama pentingnya untuk meningkatkan pemahaman budaya global tentang keperawatan yang universal dan dapat dikenali. Dari hasil penelitian lain menunjukan bahwa aspek yang paling menonjol dari webinar yaitu bahwa webinar membawa keuntungan yang sebanding dalam pengetahuan, keterampilan, dan kepuasan yang berkaitan dengan ENBC. Dari penelitian lain juga didapat hasil bahwa tidak ada perbedaan antara metode berbasis web dan tradisional seperti membaca sendiri, ceramha atau interaksi tatap muka. Demonstrasi dan klarifikasi oleh fasilitator dapat menjadi alasan untuk hasil pembelajaran yang serupa. 
Penelitian lain menyatakan bahwa partisipasi regional dan jarak jauh yang terdiri dari $30,8 \%$ dari total peserta konferensi, hasilnya menunjukan bahwa webinar adalah pendekatan yang dapat diterima oleh audiens yang kemungkinan kecil memiliki akses yang siap untuk informasi dan sumber daya yang dekat dengan rumah. Presentase smartphone yang berpartisidalam webinar yang ditargetkan untuk PABC lebih tinggi dari pada yang diperkirakan dan mungkin berhubungan dengan keinginan untuk memahami informasi yang tersedia untuk pasien kanker dan pengembangan bagi tim profesional.

Penelitian tentang pengembangan webinar tentang pemeriksaan suicide dan pelatihan penilaian resiko untuk praktik perawatan primer di pedesaan menunjukan bahwa, mayoritas peserta melaporkan bahwa webinar itu mudah diikuti dan mereka merekomendasikannya kepada sesama profesional. Mayoritas setuju bahwa webinar itu relevan dengan praktik seharihari mereka. Hal ini menunjukan bahwa webinar bermanfaat bagi penyedia layanan kesehatan dan staf yang berhubungan dengan kesehatan dan administrasi dalam praktik perawatan primer dengan pelatihan terkait bunuh diri. Dalam survei lanjutannya, mayoritas peserta melaporkan bahwa mereka merasa nyaman dan percaya diri dalam kemampuan mereka untuk bertanya kepada pasien tentang bunuh diri.

\section{SIMPULAN}

Webinar adalah metode yang layak untuk mengedukasi lintas situs institusional. Sebagian penelitian melaporkan bahwa tingkat kepuasan yang sangat tinggi dengan aksesbilitas, ruang lingkup, kualitas, dan interaktivitas webinar. Kegiatan pembelajaran berbasis web memungkinkan pendekatan yang lebih efektif dan baru untuk program internasionalisasi. Mengembangkan pemahaman tentang keperawatan sebagai hal yang universal dan dapat memiliki implikasi bagi mahasiswa keperawatan karena mendukung webinar, tidak hanya untuk kesediaan untuk bekerja di luar negeri, tetapi juga kesiapan untuk merawat populasi yang beragam.

Terdapat beberapa kendala dalam penerapan webinar, antara lain: hanya sebagian dari total peserta menyelesaikan survei demografi dan tes, karena metode pengiriman online tidak mungkin untuk melacak berapa banyak individu tambahan yang berpartisipasi tetapi tidak mengisi survei. Dengan demikian, data tentang penerimaan webinar tidak tersedia dari semua peserta. Juga tidak mungkin untuk melacak peserta mana yang hadir untuk sebagian atau seluruh webinar, yang mungkin berdampak pada bagian mana dari materi pelatihan yang mereka buka. Ukuran sampel kecil, menunjukkan bahwa replikasi data ini dengan sampel yang lebih besar diperlukan. Keberadaan infrastruktur perangkat lunak dan perangkat keras sangat diperlukan, kecepatan akses interet yang sangat tinggi dan mudah diakses, desain pendidikan yang terarah, dan memotivasi serta mendorong mahasiswa keperawatan untuk berpartisipasi dalam program pendidikan berbasis webinar. Infrastruktur teknis dan elemen manusia tetap penting dalam implementasi webinar untuk menciptakan pendidikan berkelanjutan yang lebih efektif. 


\section{DAFTAR PUSTAKA}

Undang- Undang RI No. 38 Tahun 2014 Tentang Keperawatan.

Bahrambeygi F, Shojaezadeh D, Sadeghi R, Nasiri S, Ghazanchaei E. (2018). The effectiveness of an e-learning program on nurse's knowledge and behavior for caring of patients with thromboembolism: A comparative Study. J Nurs HealthcManag, 1 (1): 1-7.

Calo, W. A., Gilkey, M. B., Leeman, J., Heisler-MacKinnon, J., Averette, C., Sanchez, S., . . . Brewer, N. T. (2019). Coaching primary care clinics for HPV vaccination quality improvement: Comparing in-person and webinar implementation. Translational Behavioral Medicine, 9(1), 23-31. doi:10.1093/tbm/iby008

Carlson, E., Stenberg, M., Chan, B., Chan, E. A., Ho, S., Lai, T., \& Wong, A. (2017). Nursing as universal and recognisable: Nursing students'perceptions of learning outcomes from intercultural peer learning webinars: A qualitative study. Nurse Education Today, 57, 54-59.

doi:10.1016/j.nedt.2017.07.006

Chiswell, M., Smissen, A., Ugalde, A., Lawson, D., Whiffen, R., Brockington, S., \& Boltong, A. (2018). Using Webinars for the Education of Health Professionals and People Affected by Cancer: Processes and Evaluation. Journal of Cancer Education, 33(3), 583591. doi:10.1007/s13187-016-11387

Eslamian, J, Moeini, M \& S. (2015). Challenges in nursing continuing education: A qualitative study. Iran J Nurs Midwifery, 20(3).
Gilkey, M. B., Moss, J. L., Roberts, A. J., Dayton, A. M., Grimshaw, A. H., \& Brewer, N. T. (2014). Comparing in-person and webinar delivery of an immunization quality improvement program: a process evaluation of the adolescent AFIX trial. Implementation science : IS, $9(1), \quad 21-21$. doi:10.1186/17485908-9-21

Gorski, M. S., Farmer, P. D., Sroczynski, M., Close, L., \& Wortock, J. M. (2015). Nursing Education Transformation: Promising Practices in Academic Progression. Journal of Nursing Education, 54(9), 509-515.

Joshi, P., Thukral, A., Joshi, M., Deorari, A. K., \& Vatsa, M. (2013). Comparing the Effectiveness of Webinars and Participatory Learning on Essential Newborn Care (ENBC) in the Class Room in Terms of Acquisition of Knowledge and Skills of Student Nurses: A Randomized Controlled Trial. The Indian Journal of Pediatrics, 80(2), 168-170. doi:10.1007/s12098-0120742-8

LeCloux, M. (2018). The development of a brief suicide screening and risk assessment training webinar for rural primary care practices. Journal of Rural Mental Health, 42(1), 60-66.

Moretz, J. G. (2010). Strengthening patient- and family-centered care: learning through webinars. Pediatric nursing, 36(3), 168-170. Retrieved from

Calo, W. A., Gilkey, M. B., Leeman, J., Heisler-MacKinnon, J., Averette, C., Sanchez, S., . . . Brewer, N. T. (2019). Coaching primary care clinics for HPV vaccination quality 
improvement: Comparing in-person and webinar implementation. Translational Behavioral Medicine, 9(1), 23-31. doi:10.1093/tbm/iby008

Carlson, E., Stenberg, M., Chan, B., Chan, E. A., Ho, S., Lai, T., \& Wong, A. (2017). Nursing as universal and recognisable: Nursing students'perceptions of learning outcomes from intercultural peer learning webinars: A qualitative study. Nurse Education Today, 57, 54-59.

doi:10.1016/j.nedt.2017.07.006

Chiswell, M., Smissen, A., Ugalde, A., Lawson, D., Whiffen, R., Brockington, S., \& Boltong, A. (2018). Using Webinars for the Education of Health Professionals and People Affected by Cancer: Processes and Evaluation. Journal of Cancer Education, 33(3), 583591. doi:10.1007/s13187-016-11387

Gilkey, M. B., Moss, J. L., Roberts, A. J., Dayton, A. M., Grimshaw, A. H., \& Brewer, N. T. (2014). Comparing in-person and webinar delivery of an immunization quality improvement program: a process evaluation of the adolescent AFIX trial. Implementation science : IS, $9(1), \quad 21-21$. doi:10.1186/17485908-9-21

Gorski, M. S., Farmer, P. D., Sroczynski, M., Close, L., \& Wortock, J. M. (2015). Nursing Education Transformation: Promising Practices in Academic Progression. Journal of Nursing Education, 54(9), 509-515.

Joshi, P., Thukral, A., Joshi, M., Deorari, A. K., \& Vatsa, M. (2013). Comparing the Effectiveness of
Webinars and Participatory Learning on Essential Newborn Care (ENBC) in the Class Room in Terms of Acquisition of Knowledge and Skills of Student Nurses: A Randomized Controlled Trial. The Indian Journal of Pediatrics, 80(2), 168-170. doi:10.1007/s12098-0120742-8

LeCloux, M. (2018). The development of a brief suicide screening and risk assessment training webinar for rural primary care practices. Journal of Rural Mental Health, 42(1), 60-66.

Moretz, J. G. (2010). Strengthening patient- and family-centered care: learning through webinars. Pediatric nursing, 36(3), 168-170. Retrieved from

Nilasari, P., Rr. Tutik Sri Hariyati. (2018). Improvement of Knowledge and Caring Behavior Through ELearning : A Literature Review. International Journal of Nursing and Health Service, volume 1.

Quelly, S. B. (2017). Characteristics Associatedwith School Nurse Childhood Obesity Prevention Practices. Pediatric nursing, 43(4), 193-199.

Renolena, b., Aste, Sevald Høyec, Esther Hjälmhultd, Lars Johan Danbolte,f, Marit Kirkevolda. (2018). "Keeping on track"-Hospital nurses' struggles with maintaining workflow while seeking to integrate evidence-based practice into their daily work: A grounded theory study. international Journal of Nursing studies, 77.

Joshi, P., Thukral, A., Joshi, M., Deorari, A. K., \& Vatsa, M. (2013). Comparing the Effectiveness of 
Webinars and Participatory Learning on Essential Newborn Care (ENBC) in the Class Room in Terms of Acquisition of Knowledge and Skills of Student Nurses: A Randomized Controlled Trial. The Indian Journal of Pediatrics, 80(2), 168-170. doi:10.1007/s12098-012$0742-8$

LeCloux, M. (2018). The development of a brief suicide screening and risk assessment training webinar for rural primary care practices. Journal of Rural Mental Health, 42(1), 60-66.

Nilasari, P., Rr. Tutik Sri Hariyati. (2018). Improvement of Knowledge and Caring Behavior Through ELearning : A Literature Review. International Journal of Nursing and Health Service, volume 1. 